\title{
Anatomy of the Ovule and Seed in Gnetum Gnemon, with Notes on Gnetum funiculare.
}

\author{
BY \\ M. G. THODAY, \\ Late Honorary Research Fellow of the Universily of Manchester and late Fellow of \\ Neronham College, Cumbridge.
}

With Plate $I$ and five Figures in the Text.

G. Gnemon。

COME time ago I had the good fortune to examine inflorescences of $\checkmark$ Gnetum Gnemon bearing a few large seeds and a number of small abortive ovules, which Professor W. H. Lang kindly placed at my disposal, and later Dr. E. N. Thomas was so good as to hand over to me two seeds of an intermediate age, a little larger than those described by Miss Berridge.

To recapitulate the structure of the female flower:-As in all species of Gnetum, ${ }^{1}$ there are three envelopes, the outer of which is succulent when ripe and is regarded here as probably foliar in nature; the middle is complex in structure, and at its tip has an angled fibrous zone, and is here regarded as the outer integument, whilst the inner covering (or inner integument) is prolonged into a freely projecting micropylar tube. Miss Berridge in Gnetum Gnemon, and the author in Gnetum africanum, have drawn attention to the closure of the lumen in the micropylar tube and the outgrowth of tissue from its wall forming a flange projecting over the tip of the middle covering.

The new material has enabled me to follow in detail the earlier stages in the closure of the lumen of the micropylar tube and the outgrowth of tissue from its wall, while providing a most useful opportunity to investigate further remarkable changes which occur in the older seed, resulting in such a complicated and altered mature structure as could not have been anticipated from the study of the earlier stages. The mature structure for the first time described presents points of interest which emphasize the comparison already made with the Bennettitalean seeds.

Early stages. Of the numerous small ovules which I examined, nearly all show some signs of the outgrowth of the cells lining the middle and lower portion of the micropylar tube.

1 Strasburger, 1872, 1879 ; Lotsy, 1899; Berridge, 1911; Thoday, 1911; Pearson, 1915.

[Annals of Botany, Vol. XXXV. No. CXXXVII. January, 192x.] 
Text-fig. I is the diagrammatic representation of the top part of a young ovule in which the changes have begun. The figure is built up from longitudinal sections connected with the series of transverse sections figured in Photos I-6, P1. I.

From the opening in the thick fleshy outer covering (c) freely projects the open tip of the micropylar tube. The micropylar canal is still open throughout, though at two places it shows signs of narrowing. The wall of the micropylar tube is already growing in thickness, and at $A f$ and $B f$ are seen projecting portions. Into $B f$ fits the tip of the middle covering. The details of this figure are better explained by reference to the photographs

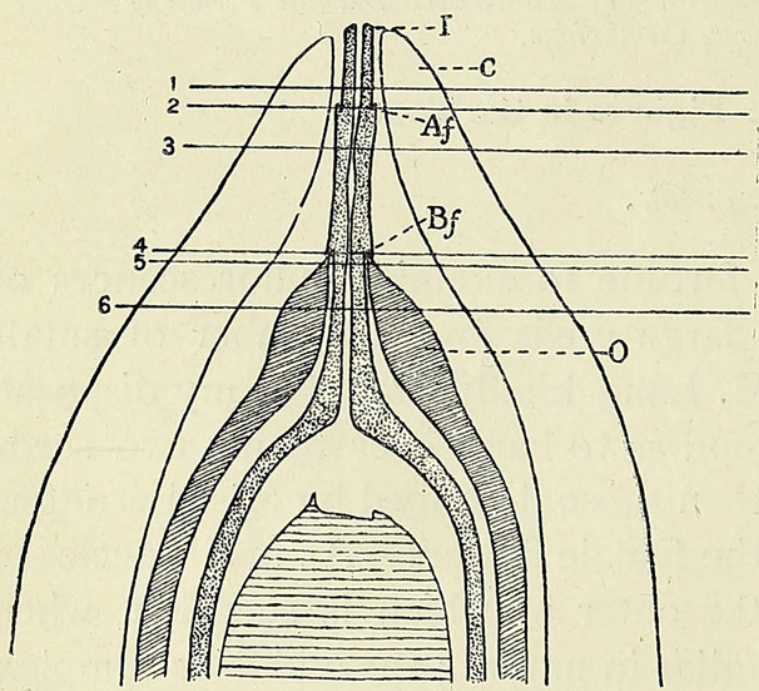

Tkxt-FIG. T. Diagrammatic view of section of young ovule of $G$. Gnemon, $3 \mathrm{~mm}$. long, in which closure of micropyle is just beginning. $C$, outer covering; $\mathrm{O}$, middle covering; I is the inner covering terminating in the freely projecting micropylar tube. $A f, B f$, are the beginnings of the projecting upward and downward flanges of the micropylar tube. I-6 represent the levels of Photos I-6, Pl. I. and descriptions of the transverse sections.

In one of the smallest ovules examined by transverse sections, a section through the apex of the ovule shows, within the outer fleshy covering, the small withered micropylar tube, with its wall composed of four or five layers of cells, and a circular lumen with a thickly cuticularized lining. A little lower (see Photo I, Pl. I), the cuticularization of the lining becomes less, and the cells of the outer epidermis become conspicuously larger, tending to project outwards to form small protuberances. A few sections lower there appears, between the outer covering and the micropylar tube, a thin ring of tissue one cell thick ( $f$, Photo 2, P1. I). When this is traced downwards it is found to be an upward continuation of the papillate outer epidermis of the micropylar tube ( $p$, Photo 2, P1. I). That is, it is formed by upwardly directed papillae, closely appressed laterally (Text-fig. I, $A f$ ). It is the beginning of the upper 'flange' described in an older ovule by Miss Berridge; in her drawing of a longitudinal section ${ }^{1}$ she figures rows of cells directed upwards, which must have had their origin as now described. In the region below these freely projecting hairs, the wall of the micropylar tube is about $6-7$ cells thick, and though the outer epidermis is fringed with prominent papillate cells they have not projected far out into the cavity between the micropylar tube and the outer covering (Photo 3, Pl. I).

At the level of the upper flange, the lumen of the micropylar tube 
becomes triangular (Photo 2, Pl. I), because of the ingrowth of the cells of the columnar epidermis ; here one or two of these cells, and a little lower many of them, are transversely divided (Photo 3, Pl. I). Farther down, the lumen widens for a short space, and becomes a narrow oval, but very soon it narrows again (as seen in Text-fig. I). This transitory wider lumen only shows that the changes which accompany closure begin first or proceed fastest at the upper and lower ends of the thickened region of the micropylar tube. In the lower part of the thickened region the lumen is quite narrow, is filled with mucilage, and its epidermal cells are both greatly elongated and subdivided into rows; the sub-epidermal cells also are divided radially. The papillae produced by the outer epidermal cells project more freely outwards, and some of the cells below this outer epidermis are dividing radially.

The next section figured (Photo $4, \mathrm{Pl}$. I) cuts the tip of the outer integument (middle covering), which is buried in the hairs at the base of the thickened region of the micropylar tube. The tip of the outer integument is fringed with papillate cells with thickened, often slightly lignified, walls, which tend to aggregate into groups, and are shown in the photo at $\mathrm{x}$. The hairs of the edge of the inner integument are often prolonged between them so that they appear in section as free groups of cells surrounded on all sides by hairs. It is difficult or impossible even at this stage to make out clearly the line of separation between the tip of the outer integument, micropylar tube, and hairs; the epidermis of both coverings being papillate, they fit closely together.

Some way below the level of the tip of the outer integument the lumen of the micropylar tube widens, and the elongated lining cells gradually resume their regular shape. The lumen is at first triangular (Photo 6, Pl. I) and then enlarges to form the large cavity surrounding the apex of the nucellus. Into this cavity projects the shrivelled tip of the nucellus with its indurated walls (Photo I6, Pl. I), to me reminiscent of Prof. Seward's description of the small nucellar beak in Williamsonia scotica. ${ }^{1}$

In this ovule there is no sign of lignification of any of the tissues of the outer integument, the inner layer (which ultimately develops into a strongly lignified zone of cells like that described in $G$. africanum) being here composed of small closely compacted cells, isodiametric in transverse section. There are already signs of radial growth on the shoulder of the outer integument to form the expanded region found in the older seed. The other small ovules examined by transverse section differed only in detail from the one chosen for the above description.

Other small ovules were cut in longitudinal section. One showed as yet no sign of the formation of a flange or thickened region or of the 
ingrowth of the inner epidermis of the micropylar tube. Photo I5, Pl. I, shows the tip of this ovule.

Each of the others had a small flange composed of a few hairs in which the tip of the outer integument was buried. In one of these the lumen of the micropylar canal was still open, although the ingrowing epidermal cells had almost everywhere divided once and the epidermal layer three or four times. In another the flange was more developed and the wall of the tube thicker. The epidermal cells that grow out to form the flange had already divided into radial rows, as figured by Miss Berridge. ${ }^{1}$ The middle covering in this ovule had thickened and the formation of the expanded shoulders was already beginning.

In these young ovules there is much mucilage, both in the lumen and in the cavity between the micropylar tube and the nucellar apex. The nucellar apex is composed of rows of cells radiating outwards, and degenerating in the region of the pollen-chamber. Photo 16 , Pl. I, shows the degenerating tissue above the radial rows of cells in the nucellar apex.

Seeds about $8 \mathrm{~mm}$. long. The two seeds about $8 \mathrm{~mm}$. long were only a little more advanced than the stage described by Miss Berridge (1911), and their structure is easily comparable with that shown in her Fig. 1. Near the apex of the micropylar tube the upwardly directed tissue growing out from the wall of the micropylar tube was more sharply marked than in Miss Berridge's Fig. I, and appears as a free ring in transverse sections above the level of its origin from the tube. In this region the proliferated wall of the now closed micropylar tube is composed of clearly distinguishable and beautifully regular rows of cells, and is brought closely into contact with the outer covering; indeed in some places their boundaries ate indistinguishable. The growth in thickness of the micropylar wall as a whole has resulted in the closing both of the cavity between it and the outer covering and the lumen itself, which is now quite obliterated.

In the lower part of the closed portion of the tube the wall is narrower and the cavity tends to reappear, but is blocked by a solid mass of proliferated epidermal cells which have grown out more irregularly as papillae with enlarged ends and are now strongly lignified, thus forming a very conspicuous rod of cells, something like, though much more developed than, the core described in $G$. scandens, and figured in a former paper. ${ }^{2}$

Just below this papillate region the open tube has a cuticularized lining; near the bottom of the lower flange the lining is torn, but the tube is nowhere broken across.

When the level is reached at which the tube is supported by the tip of the middle covering the lining is again entire and cuticularized. The tip of the middle covering is still buried in the hairs of the downwardly projecting flange.

1 Berridge, 1911, p. I 4 0.

2 Thoday, 1911; Fig. 9, Pl. LXXXVI. 
The ovules show the structure of the middle part of the seed more satisfactorily than do the older seeds, where more lignification has made sections of this part almost unattainable. The extreme tip of the outer integument is parenchymatous, but a little lower a band of lignified tissue appears on its inner edge (Photo I 4, Pl. I), and as soon as the terminations of the vascular bundles are reached this band becomes rayed, each ray projecting opposite a vascular bundle. At first there are four or five vascular bundles, and four or five rays to the fibrous band as described in G. africanum, in a former paper, ${ }^{1}$ but a little lower a large number appear in the sections. Near the apex of the middle covering the cells of the thick-walled tissue, and also of the outer parenchymatous tissue, which is here expanded to form the widened shoulders of the seed, are radially elongated and arranged in radial rows, and a palisade layer is visible between the thick- and thin-walled cells, but this soon becomes irregular. Below the shoulders the thickening of the walls almost ceases at this stage, and they are no longer lignified, though a differentiation into inner and outer layers is visible throughout.

The oval pointed fleshy seeds of G. Gnemon have been figured by Lotsy, ${ }^{2}$ but the seeds here described in detail were of much greater size.

The mature seed. Text-fig. $2 \mathrm{~A}$ is drawn to scale from a mature seed of $G$. Gnemon $3.3 \mathrm{~cm}$. long. Half of the outer covering has been pared away, leaving exposed the outer integument, which is distinctly angled.

The apex of the closed micropylar tube is here seen to be fused with the outermost covering, forming a sort of stopper. At the same time the tip of the middle covering $(O)$ is no longer fused with the lower flange of the micropylar tube, but the outer covering has grown up and carried with it the 'stopper', breaking the micropylar tube across at its weakest point. The apex of the middle covering is now at a considerable distance below the stopper and a bit of broken micropylar tube (B) sticks out from it.

A section of the apex of the seed is seen more highly magnified in Text-fig. 2 D. The indurated open tip of the micropylar tube, which is unusually long in this particular specimen, yet does not extend to the surface of the outer covering, is seen in section surrounded by a long upwardly directed flange $(A f)$ which has grown out from the wall of the tube lower down. The outer surface of the wall below this flange is fused with the outer covering. In this region the wall of the tube is thickest, and the lumen is filled with thin-walled closing tissue $(p)$, derived from the ingrowth of the epidermal cells. Below this thin-walled tissue there is a gap $(G)$ with a torn irregular lining; here part of the wall of the tube alone is left fused to the outer covering, the inner part of the tube with its mass of closing tissue having been dragged out when the tube broke across (micropylar beak, Text-fig. 2 A), owing to the greater growth in length of the outer

$$
1 \text { Ibid., p. II } 5 \text {. }
$$$$
{ }^{2} \text { Lotsy, } 1899 .
$$ 
covering. The section shows the great width of the lower expanded part of the now hollow flange.

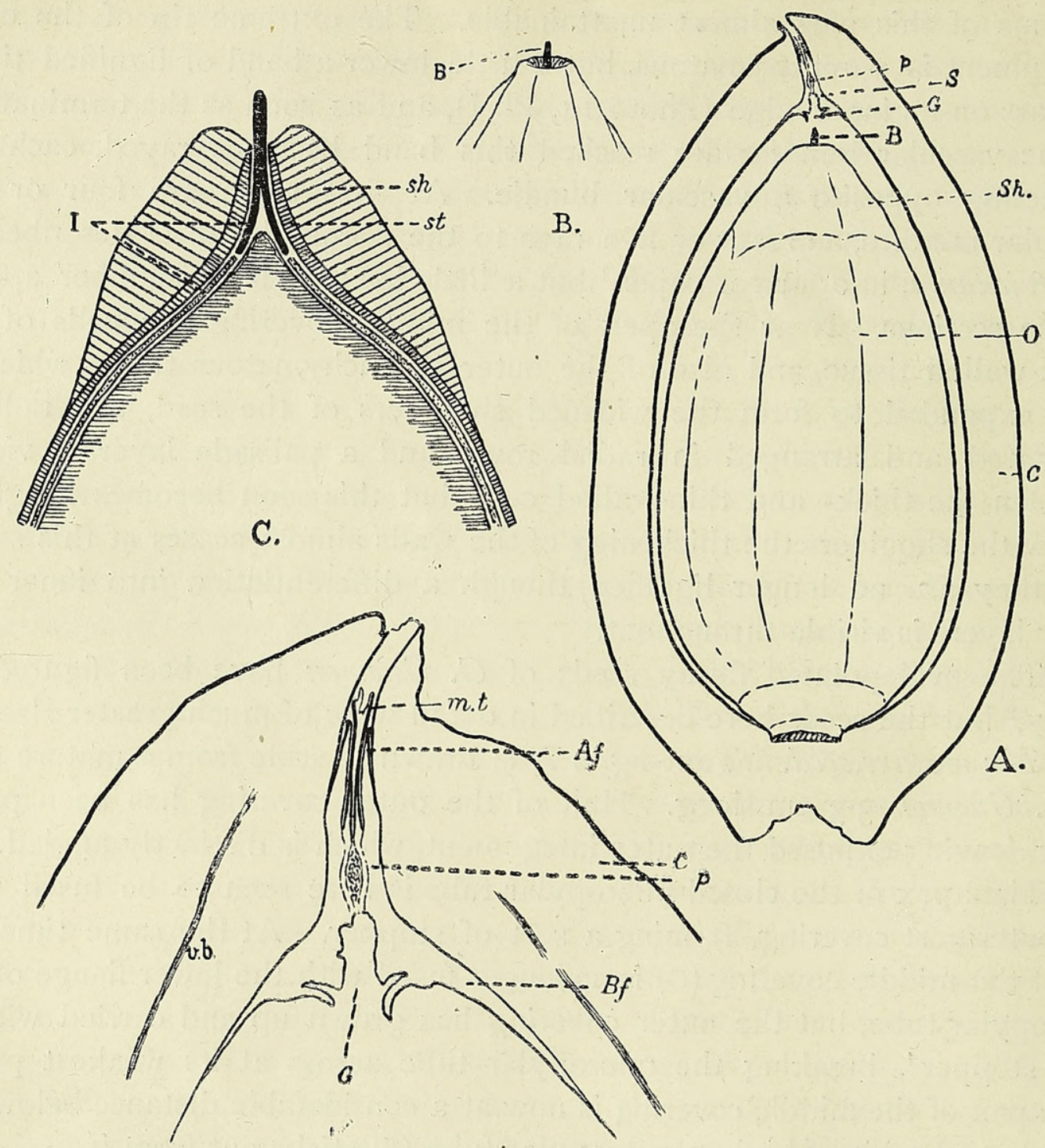

D

Text-Fig. 2. Drawn from mature seed of G. Gnemon, $3 \mathrm{~cm}$. long, described in text. A is the whole seed enclosed in inner and middle coverings seen in situ, with half the outermost covering pared away to show the top part of the micropylar tube, the stopper (s), in which $p$ is the closing tissue, and G the gap out of which the beak (B), the bottom part of the micropylar tube, has been torn. $\quad C$ is the outermost covering, $O$ the angled outer integument composed of an inner hard layer and an outer soft layer, the latter expanded at $S h$ over the shoulders of the seed $(x 5)$. $B$ is the apex of the outer integument looked at from above, showing the beak (B) projecting from a depression $(\times 5)$. C is drawn from the median section of $B$. The nucellus, filled with endosperm, is seen enclosed firstly by the inner integument ( $\mathrm{I}$ ), parenchymatous below (dotted area) and lignified above (blackened beak); secondly, by the tip of the outer integument, with its expanded soft outer layer $(s h)$ and stony inner layer $(s t)(\times 10)$. D is the apex of A more highly magnified ( $\times 18$ ), and shows the tip of the outermost covering (c) with the stopper. $A f$ and $B f$ correspond to the upward and downward growing flanges of the micropylar tube in Text-fig. I. m.t.:= the tip of the micropylar tube $; p=$ closing tissue! $\mathrm{G}=$ gap $; v . b_{0}=$ vascular bundle.

Text-figs. $2 \mathrm{~B}$ and $\mathrm{C}$ are taken from the apex of the middle covering (outer integument) of the same ovule, and show the broken portion of the micropylar tube (B) projecting upwards, both as seen in the solid object and 
in section. Minute examination of the top part of this beak-like structure shows its irregular outer surface corresponding to the irregular inner surface of the cavity (G) from which it was torn ; it is heavily lignified throughout, and the lignification extends (Text-fig. $2 \mathrm{C}$ ) down to the level opposite the nucellar tip, below which the inner integument is parenchymatous. The tip of the middle covering is also seen in this figure with its stony inner layer $(s t)$ and soft expanded outer layer $(s h)$.

Text-fig. 3 represents a longitudinal section of another seed in which the tip of the micropylar tube reached the surface of the outer covering. Below the open portion of the tube with its thickened cuticularized lining and upwardly directed short corky flange, there is the widened part fused to the outer covering. In this seed a strand composed of a few of the thickened cuticularized cells forming the original lining of the micropylar tube could be traced down the middle of the solid portion; lower down, this widened as the part of the tube at an early stage more widely open, but now filled with papillae, is approached. A few thylose-like papillae are still left, unlike the other seed in which they had all been torn out by the breaking away of the rest of the tube.

Cross-sections show even more clearly that what has been torn away is the solid

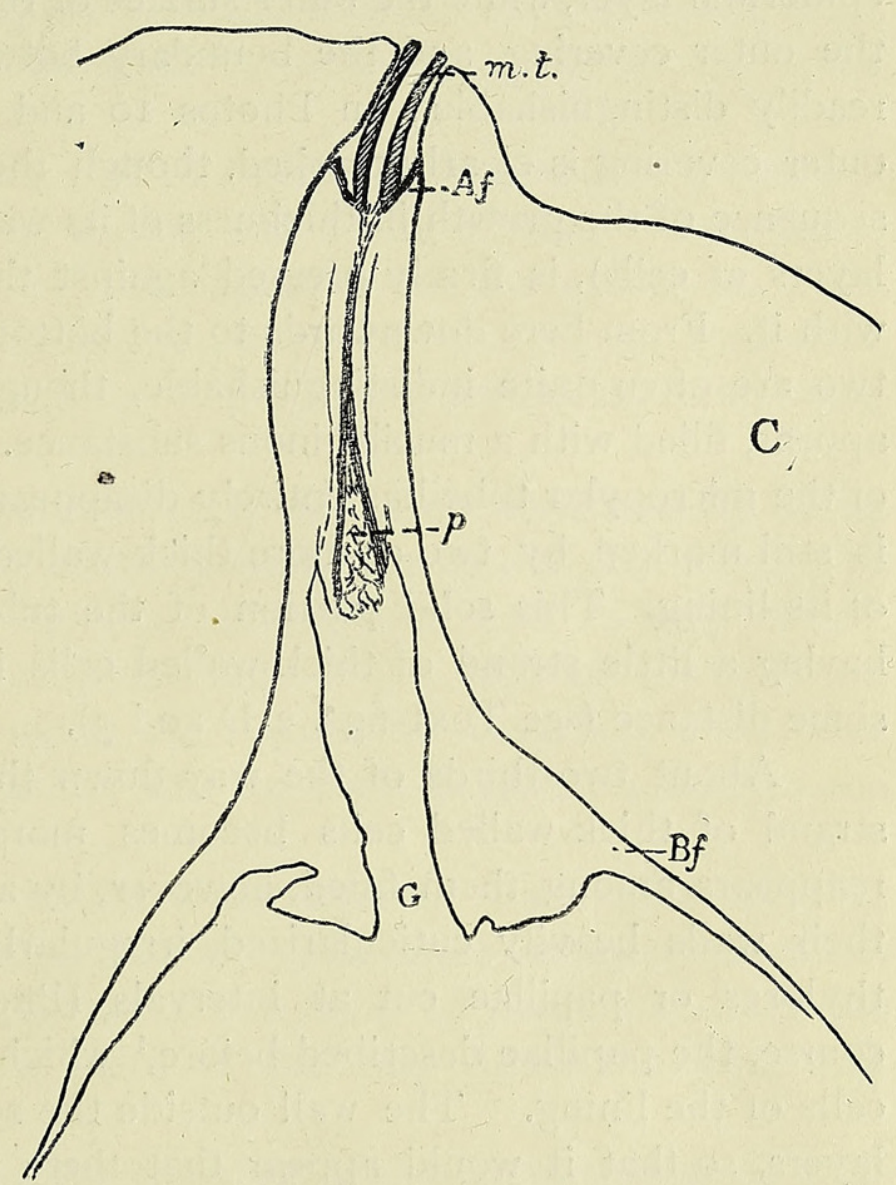

TEXT-FIC. 3. The apex of another mature seed of Gnetume Gnemon. The free upward flange $(A f)$ is much smaller than in Text-fig. 2 , and the papillate region $(p)$ more clearly seen. The free part of the micropylar tube $(m . t$.$) is shorter and comes to the surface of the outermost$ covering (C). Bf, and $G$ as in Fig. 2 D. closing rod of papillae formed from the epidermal lining of the tube, and with it some of the sub-epidermal layers, the part of the wall formed by subdivision of the outer layers being left. In a series of transverse sections, taken from above downward, through another mature seed very like the last, the first few sections cut through the outer covering with its round excentric lumen, limited by a definite epidermis, and with the free micropylar tube projecting through it (Photo 7, Pl. I). The latter is composed entirely of thickened cells with a strongly cuticularized internal 
epidermis. A short way down (Photo 8, Pl. I) the free portion of the upwardly projecting flange is cut (see $A f$, Text-figs. 2 and 3 ), its inner edge fringed by crushed rows of cells with corky walls; growth from a cork cambium has occurred, cutting off dead and empty cork-cells over the exposed free region of the flange, and thus protecting the delicate tissues beneath. Photo 9, Pl. I, is from a section below the free flange, and shows the base of the cork cambium at the junction of the micropylar tube and the flange. The lumen of the tube is narrowed by the subdivision of the epidermal layer, while the outer surface of the proliferated wall is fused with the outer covering, and the boundary between them ( $e$, Photo 9$)$ is not readily distinguishable; in Photos IO and II the inner epidermis of the outer covering is clearly marked, though the surface of the tube, as a consequence of the growth in thickness of its wall (now composed of 20 or more layers of cells), is firmly pressed against the outer covering and is fused with it. From here downwards to the bottom of the flange the limits of the two are often quite indistinguishable, though at intervals irregular cracks appear, filled with a mucilaginous substance. In Photo I0, Pl. I, the lumen of the micropylar tube has entirely disappeared, though its original position is still marked by two or more thick-walled cells which used to form part of its lining. This solid portion of the tube, sometimes, but not always, having a little strand of thick-walled cells in the centre, is continuous for some distance (see Text-figs. $2 \mathrm{D}$ and 3 ).

About two-thirds of the way down the wide region of the tube the strand of thick-walled ceils becomes more prominent, and an opening reappears among them filled, however, by a solid mass of large cells with their walls heavily cuticularized, irregularly orientated, and looking like thyloses or papillae cut at intervals (Photo II, Pl. I). These are, of course, the papillae described before, ${ }^{1}$ which grew out from the epidermal cells of the lining. The wall outside the solid mass is composed of fewer layers, so that it would appear that there has been much less activity of the outer layers of the tube wall; as a consequence, the lumen in this region has not been closed by external pressure but by the ingrowth of papillae.

The papillate region is very short; the papillae suddenly become torn and few in number, and the whole middle of the tube next disappears, having, as was seen in the longitudinal section, been broken across and torn out. In Photo I 2 there is consequently a large open, often mucilaginous cavity (G), irregularly lined by torn cells and bounded by a few layers of cells firmly fused to the outer covering.

Photo I $3, \mathrm{Pl}$. I, ${ }^{2}$ passes through the sudden enlargement of the outer layers of the micropylar tube to form the downwardly directed flange $(B f)$ which in the young seed projects over the tip of the middle covering

\footnotetext{
${ }^{3}$ p. 7.

${ }^{2}$ N.B. Photos 13 and 14 are on a smaller scale than the others of this series.
} 
(see, Text-figs. I and 2 B). A smaller lateral irregular gap $(g)$ is seen in the flange, probably similar to that seen in Text-figs. $2 \mathrm{D}$ and 3 . It seems likely that these gaps represent the places into which the middle covering originally projected.

Owing to the very considerable growth and stretching of the apex of the seed between the stage $8 \mathrm{~mm}$. long and these mature seeds, not only is the tip of the middle covering no longer buried in the hairs of the flange, but the flange has been carried so far upwards that there is a considerable interval during which sections pass through, first the outer covering only, and then the outer covering enclosing the torn-out, beak-like portion of the micropylar tube.

Cross-sections through the top of this projecting portion of the micropylar tube show its irregular torn surface and a wall of three or four layers of cells; the lumen is closed by the ingrowth of the epidermal cells. Lower down, its outer surface is smooth, bounded by a regular epidermis. All the cell-walls are heavily lignificd, the projecting part of the tube being thus a solid little 'beak'.

When the series of cross-sections reach the parenchymatous tip of the middle covering it is found to be clasping firmly the base of the micropylar tube, which is still strongly lignified throughout, and is still closed. Photo I4, Pl. I, shows the micropylar tube a few sections lower down, with a slit-like opening, surrounded by the middle covering, which now has its inner layers heavily lignified and its outer parenchymatous tissue widely expanded.

Below this level the thick-walled inner layer of the middle covering persists to the base of the ovule, but the innermost covering becomes thin-walled and is seen in section as a thin strip of tissue free from the middle covering, fusing, about a third of the way down the seed, with the nucellus (see Text-fig. 2 C).

The structure of the outermost covering is similar to that in G. africanum, which is described in more detail in a former paper. ${ }^{1}$ The middle covering is much as in the ovules $8 \mathrm{~mm}$. long, except that the inner stony layer is more heavily lignified.

Treo abnormal ovules. There were two curious features about the two ovules $8 \mathrm{~mm}$. long. They were both flattened on one side, throughout the main body of the seed, being roughly triangular in form, like the seeds of Ephedra.

Also just inside the base of the inner covering there arose from the nucellus a ring of tissue, which was more developed in one ovule than in the other, but in both extended freely for some distance upwards like a rudiment of a fourth covering. A somewhat similar development, arising, however, between the outer and inner integument, has been 
recorded in an earlier paper on an abnormal ovule of Welwitschia, ${ }^{1}$ and Pearson $^{2}$ described a fourth covering in the fertile ovule found at the base of a male spike in G. africanum.

\section{G. funiculare.}

The material of $G$. funiculare, kindly sent me from Buitenzorg, was not very well preserved, and has therefore not been investigated in great detail.

The small ovule. In the small ovules, up to about $5 \mathrm{~mm}$. long, the three coverings are all free from one another. The outer one is already very fibrous. The upper portion of the micropylar tube had a very heavily cuticularized lining, like that of Ephedra, ${ }^{3}$ and contained a mass of hardened mucilage. Lower down, just above the tip of the middle covering, the lining of the tube ceases to be cuticularized, and the regularity of its cells is disturbed by a tendency to grow out into papillae. There seems to have been no increase in thickness in the wall of the tube, which consists of about the same number of layers, $5^{-7}$, throughout, and at this stage there is no flange. Some of the larger aborted ovules showed a few large irregular hairs growing out from the surface of the micropylar tube to form the flange.

From just above to some distance below the tip of the middle covering the micropyle is closed by the subdivided papillae, which form a solid rod of remarkably definite appearance, even more sharply defined than in the papillate region in G. Gremon. ${ }^{4}$

The tip of the middle covering expands at the shoulders of the seed, but at this stage contains very little lignified tissue. Below the shoulders there is a layer of somewhat thickened horizontally running fibres. In the lower portion of the inner integument, below the micropylar tube, there are a large number of wide and strongly lignified fibres, which die out at the level of fusion with the nucellus.

The seeds. In the large seeds, about $2 \mathrm{~cm}$. long, the outer covering is still more fibrous, there being two distinct zones of fibres, an inner and an outer, with thin-walled tissue between. At the apex the micropylar tube is closely approximated to the outer covering, and it appears to be fused with it for a short distance. The fused portion of the tube is, however, very short ; it becomes free from the outer covering almost at once; there is a small flange, composcd of a very few gigantic and very strongly lignified hairs or papillae, some above the fused region upwardly directed, some projecting downwards over the tip of the middle covering; they more or less fill up the chink between the top of the middle covering and the outer covering. The

\footnotetext{
1 Sykes, 1910, Fig. I2, p. 199.

3 Thoday and Berridge, 1912, p. 964.
}

2 Pearson, 1915, p. 322.

4 Photo II, Pl. I. 
tube is closed throughout this narrow region by the ingrowth of fairly regular epidermal cells with strongly lignified walls.

The middle covering is much more differentiated, and except just at its apex is now fused throughout with the outer covering, as in G. scandens. $^{1}$ In its expanded portions there are four large masses of lignified

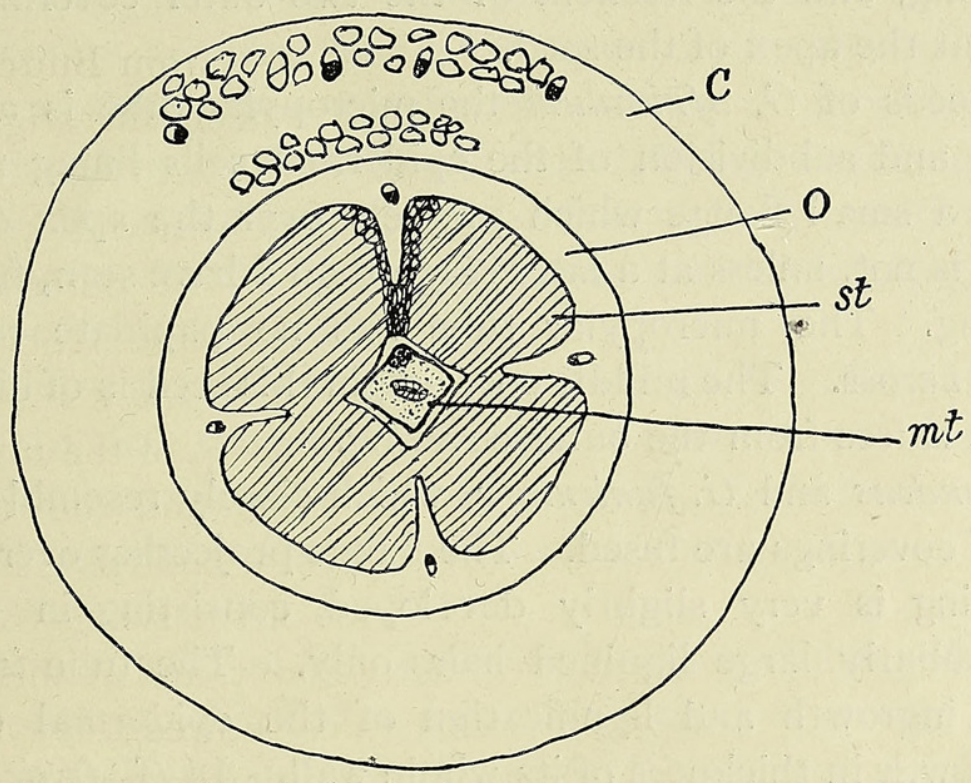

TEXT-FIG. 4. G. funiculare. Cross-section of apex of seed, showing two bands of fibres in outer covering (c), 4 -lobed stony layer $(s t)$ of middle covering $(0)$, and lignified micropylar tube $(m t)$.

fibres (Text-fig. 4) which, lower down, pass into a heavily lignified layer composed of numerous horizontal fibres and a sort of indefinite palisade layer of fibres elongated at right angles to these; the outer layers arc parenchymatous.

The fibres in the inner integument have not much, if at all, increased in number, but the outer covering is very fibrous in this seed, not succulent as in G. Gnemon.

\section{Comparative Summary of the Seeds of Four Species of Gnetum.}

The seeds of G. Gnemon are by far the most interesting of the four species I have seen, because of the complex arrangement for the closure of the micropyle. In the mature seed the canal of the micropylar tube is not only closed by the ingrowth of the epidermal cells, and by pressure due to the great increase in thickness of its wall, but the tube itself is also firmly fused to the outer covering. An upwardly directed flange, covered with cork which protects its delicate tissues, and a downwardly directed flange also fused to the outer covering, complete the solid stopper-like arrangement. Just above this lower flange the micropylar tube is broken across, and the papillate cells, which in the earlier stages fill up the cavity of the lower part

1 Thoday, 1911, D. I 118. 
of the tube, where the wall has not increased so much in thickness, are mostly drawn out with the broken base of the tube. Thus the lower end of the tube is now found projecting as a solid, hard, lignified beak from the top of the middle covering.

Other characteristics of $G$. Gnemon are the angular outline of the middle covering, and the freedom of the two outer coverings from each other except at the apex of the seed.

In the seeds of $G$. africanum the micropylar tube is also closed by the ingrowth and subdivision of the epidermal cells lining the tube, and there is also a small flange which projects over the apex of the middle covering, but is not, unless at a later stage than I have seen, fused on to the outer covering. The micropylar tube has no papillate region, and is nowhere torn across. The middle covering in this seed is of highly complex structure. It is free from the outer covering.

In $G$. scandens and G. funiculare, which closely resemble one another, the two outer coverings are fused. The flange projecting over the tip of the middle covering is very slightly developed, consisting in G. funiculare of a few peculiarly large lignified hairs only. The tube in G. scandens is closed by ingrowth and lignification of the epidermal cells, and the concurrent growth in thickness of its whole wall. In $G$. funiculare the wall of the tube does not increase in thickness; consequently there is no pressure to assist in the closing of the lumen, and the ingrowing epidermal cells are looser and more irregular, like the papillate region in G. Gnemon. In $G$. scandens the middle covering, and in $G$. funiculare the outer and inner also, contain many strongly lignified fibres.

These four species thus show very different degrees of efficiency in the closure of the micropyle. In G. funiculare and G. scandens there is no gap between the two outer coverings of the ovule to fill, for these are fused in the mature seed, so there is no need of an elaborate stopper, and the small flange of hairs growing out of the micropylar tube and adhering to the tip of the middle covering is sufficient. In G. africanum and G. Gnemon the outermost covering is free from the middle, but in the former species the chink between the two is not completely closed, the stopper being well developed and projecting over the middle covering, but not being adherent to the outermost covering. In G. Gnemon the closing arrangement is complete, and the adherence of the stopper to the outermost covering has resulted in the breaking of the tube and the separation of the stopper from the micropylar beak.

\section{Comparison with the Bennettitales.}

From time to time comparisons have been made between the Gnetales and the Bennettitales; recently both Miss Berridge and I have drawn 
attention to the resemblances in their seeds. ${ }^{1}$ If there is any force in this comparison, it is certainly augmented by the structure of the mature seed of $G$. Gnemon.

Although it is not desirable to draw from these resemblances any conclusions as to affinity, it is at least possible that the more easily investigated modern seeds may throw some light on the fossils, and it may well be that common ancestors are responsible for some of the similar features. The remarkable growth-changes now described in the development of the seeds of Gnetums may help us to interpret the differing arrangements described in the various Bennettitalean seeds, and it is at least conceivable that these differing arrangements are to be ascribed to the varying stages of maturity at which the seeds had arrived.

A detailed comparison between some of the Bennettitalean seeds described up to that time and the seeds of Gnetum was made in a former paper, ${ }^{2}$ and the recent descriptions of Cycadeoidea by Wieland and Seward's ${ }^{3}$ account of the small ovules of Williamsonia scotica ${ }^{4}$ seem to corroborate these early attempts.

In the small ovules of $W$. scotica the apex of the nucellus is composed of radiating rows of cells, and in some cases there is no sign of any disintegration and no pollen-chamber. ${ }^{5}$ In other cases there appears to be a small space at the apex, the sides of which extend upwards as a 'shrivelled beaklike prolongation', ${ }^{6}$ suggestive of the pollen-chamber of Gnetum, with its thickened and indurated walls, which in longitudinal section are seen projecting upwards like a minute beak. The seeds were not sufficiently well preserved, and probably too immature ${ }^{7}$ for much differentiation in the integument. Originating near the base of the seed, Seward found in longitudinal section 'two strips of indistinct, thick-walled and short cells which have no epidermis and are almost certainly portions of a tissue which was originally broader. At a higher level the short cells become rather larger and much longer', 8 and are better preserved. These loose strips of tissue may represent the thickened fibrous layer of an integument like that of Gnetum, the rest having failed of preservation. At a higher level these strips approach the nucellus and join with it: this level would correspond with that of the origin of the inner integument in Gnetum, and, as in Gnetum, an expanded tissue is found over the shoulders of the seed, composed of thickened and radially elongated cells limited by a well-defined and characteristic epidermis. This epidermis ceases above the shoulders of the seed, just at the level where the middle covering ceases and we find the

1 Sykes, 1912, p. 217 ; Berridge, 1911, p. I40; Thoday (Sykes), 1911, pp. II 25-30; Thoday and Berridge, 1912, pp. $978-9$.

2 Thoday, M. G., 1911, pp. I I 25-30.

4 Seward, 1912.

6 Ibid., Fig. I8, Pl. II.

3 Wieland, 1912, Fig. 2.

Ibid., pp. I IO-I I.

5 Ibid., Fig. 3 D, p. I I I.

7 Seward, 1912, p. I I 5 . 
expanded flange of the inner covering in Gnetum. The micropyle is widely open at the apex, but lower down, where the canal is probably slit-like, it may, if the comparison with Gnetum be correct, be already partly closed.

The earlier descriptions of Cycadeoidea made

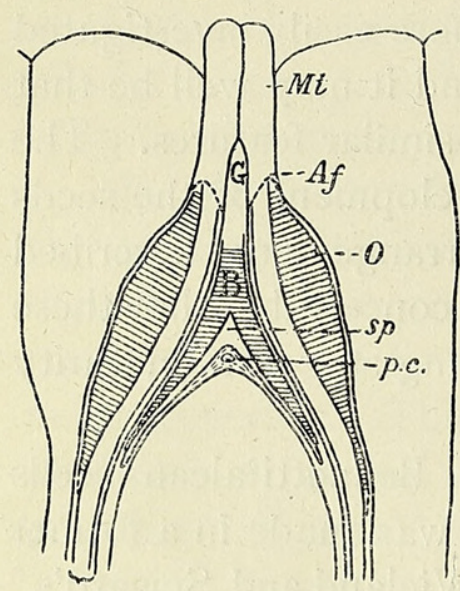

Text-fig. 5. Apex of seed of $B$. Morierei (from Lignier, 1894, relettered for purposes of comparison). $M t$ = micropylar tube with projecting spurs (Af) comparable with stopper and downward flange in Gnetum, projecting over tip of integument (O). (The dotted line at the base of the flange is inserted.) $\mathrm{G}=$ space between stopper and beak (B) described by Lignier as the canal of the micropylar tube; $\mathrm{B}=$ Lignier's nucellar beak, compared here with the beak formed by the broken-off base of the micropylar tube in Gnetum; $s p=$ space between beak and nucellus called by Lignier the pollen-chamber; p.c. $=$ Lignier's 'corpuscular mass' in the apex of the nucellus comparable in position with the pollen-chamber in Gnetum. possible only a rough comparison with Bennettites and the mature seed of Gnetum, but the later described mature seeds of $C$. turvita ${ }^{1}$ and C. Dartoni ${ }^{2}$ make the resemblances much clearer. In these seeds the outer layer of the integument is 'palisaded' throughout, but most strongly at the shoulders of the seed, where it is expanded into five or six wings, like B. Morierei. At the top of these expanded shoulders there is a break, beyond which begins the micropylar tube proper ; the stony layer of the integument is not prolonged over the micropylar tube as was at first erroneously thought. ${ }^{3}$ Thus the whole arrangement is quite comparable with that in $G$. africanum; ${ }^{4}$ the micropylar tube is even similarly filled with thin-walled tissue, and appears to be a separate organ from the integument which forms the shoulders of the seed.

There is no nucellar beak described or figured in these seeds; as they are at a stage when the embryo is well developed, it is not surprising that the relations of the micropylar tube to the nucellus, \&c., are not well defined.

Lignier's description of Bennettites Morierei, ${ }^{5}$ also a seed with fully developed embryo, has up till now not been comparable with the other seeds, either of the Bennettitales or of Gnetum. In my earlier paper on Gnetum, ${ }^{6}$ I compared the detailed structure of its winged integument with that of Gnetum and Ephedra, 'but it was obvious that the relations of the nucellus with the micropylar tube and integument in Bennettites were very confusing.' The suggestions then made are strengthened by the current investigation of G. Gnemon; the remarkable arrangement found at the apex of that seed, exemplified in Text-fig. 2, resulting frcm complicated growth-changes reminds one most forcibly of Lignier's figures

1 Wieland, 1911, Fig. I5 C ; 1912, Pt. VI, Fig. II. He compares this seed to Gnetum, but his figure of the 'leafy' seed of Gnetum seems to be based on a misconception.

2 Wieland, 1916, p. I 33.

3 Ibid., 1912, Pl. VI, Fig. 6.

4 Ibid,; see description of Fig. I I.

5 Lignier, 1894.

6 Thoday, 1911. 
of the seed in B. Morierei (see Text-fig. 5), the freely projecting beak-like base of the micropylar tube corresponding to his 'nucellar beak', and the space within it to his 'pollen-chamber' $;^{1}$ the small lysigenous space described by him at the apex of the nucellus, and stated to have been once seen to contain objects which resembled pollen grains, ${ }^{2}$ corresponds in position to the pollen-chamber in the young seeds of Gnetum. Lignier thought the integument and micropylar tube were continuous, though there was no detailed resemblance between their respective cell organization; and it may well be that the micropylar tube was here, as in Gnetum, fastened by a flange to the top of the outer integument, ${ }^{3}$ while the projecting 'beak' is really the broken base of the same micropylar tube.

Miss Berridge, while comparing the seed of G. Gnemon to B. Morierei, suggested that the nucellar beak in the latter is comparable to the closing tissue of the micropylar tube in G. Gnemon; Lignier (1911), in reply, draws attention to the massive structure of the nucellar beak in B. Morierei, which he says is 'totalement indépendant du tube micropylaire', while the tissue closing the micropyle is produced 'au-dessus du sommet nucellaire', that is to say, there is a space between the stopper, i. e. the closed apex of the micropylar tube, and the beak; there is just such a space now described in the mature seed of G. Gnemon, between the stopper and the broken-off base of the micropylar tube, the whole of which broken-off base (and not the closing tissue only) I am here comparing with the so-called ' nucellar beak' in B. Morierei.

\section{SUMMARY.}

This paper describes the series of changes which occur in the development of the seed in G. Gnemon. The young seed has three coverings, the inner of which projects freely upwards as the micropylar tube; by a series of growth-changes, the canal of the micropylar tube becomes closed and its apical region broken off from the base.

This apical region then forms a sort of 'stopper' firmly fused by a flange on to the outer covering. By the growth of the outer covering the stopper is carried up away from the lower part of the tube; a considerable distance is thus established between the stopper and the top of the middle covering, over which the flange originally projected.

The broken-off basal part of the tube then projects as a sort of 'beak' through the opening in the top of the middle covering; this beak is solid

1 Thoday, 1911, p: I 128.

2 Berridge, 1911; Thoday, 1911. In some seeds of G. Gnemon, Berridge, Fig. I, and my two ovules $8 \mathrm{~mm}$. long, the lower part of the micropylar tube below the closed region is lined by a ragged torn layer of cells very suggestive of Lignier's 'lysigenous pollen-chamber'.

3 Since the above was written Wieland (1916) has discussed Miss Berridge's and my earlier suggestions, and I am quite of his opinion that the above resemblances require further elucidation and comparison with the seeds. 
and strongly lignified down to the level of the shoulders of the seed. When the beak or basal part of the tube is broken off from the upper part, some of the closing tissue of the stopper is generally dragged out, leaving a cavity in the bottom of the stopper.

An attempt is made to compare more closely than before the series of seeds belonging to the different species of Gnetum with some of those of the Bennettitales. Williamsonia scotica, with its simple plan, is compared with a young seed of Gnetum, and new light seems to be thrown on the complex structure of Cycadeoidea and Bennettites Morierei by the mature seed of Gnetum Gnemon.

The greater part of this work was done in the Manchester University Botanical Laboratory. My thanks are due to my husband, Professor D. Thoday, for his assistance in the preparation of the text-figures.

\section{LITERATURE CITED.}

Berridge, E. M. : On some Points of Resemblance between Gnetalean and Bennettitalean Seecis. New Phyt., x, I9II.

Lignier, O.: Végétaux fossiles de Normandie. Structure et affinités du Bennettites Morierei. Bull. de la Soc. Linn. de Nor., I 894 .

: Le Bennettites Morierei. Bull. de la Soc. Bot. de France, vol. lviii, sér. 4, I9I I.

Lotsy, J. R. : Contributions to the Life-history of the Genus Gnetum. Ann. Jard. Bot. Buit. (2), i, 1899 .

Pearson, H. H. W. : Notes on the Morphology of certain Structures concerned in the Reproduction of the Genus Gnetum. Trans. Linnean Soc., viii, I9I5.

Seward, A. C. : A Petrified Williamsonia from Scotland. Phil. Trans. Roy. Soc., B., cciii, I9I2.

Sykes, M. G. : The Anatomy and Morphology of the Leaves and Inflorescences of Welwitschia mirabilis. Ibid., cci, I9I 2.

Thoday, M. G. (Sykes, M. G.): The Female Inflorescence and Ovules of Gnetum africamum, with Notes on Gnetum scandens. Ann. Bot., xxv, I9II.

and BERRIDGE, E. M. : The Inflorescences and Flowers of Ephedra. Ibid., xxvi, I9I2.

Wieland, G. R.: A Study of some American Fossil Cycads. Part V. Further Notes on Seed Structure. Amer. Journ. of Science, xxxii, I9I I.

I9I2.

: On the Williamsonian Tribe. Ibid., xxxii, I91 I.

: American Fossil Cycads. Carnegie Institute. Pt. I. I906.

Ditto. Pt. II. I9I6. 
DESCRIPTION OF FIGURES IN PLATE I.

\author{
Illustrating Mrs. M. G. Thoday's paper on Anatomy of the Ovule and Seed in Gnetum Gnemon, \\ with Notes on Gnetum funiculare.
}

\title{
G. Gnemon.
}

$\mathrm{C}=$ outermost covering $; \mathrm{O}=$ outer integument $; \mathrm{I}=$ inner integument; $\mathrm{N}=$ nucellus.

Figs. I-6. Series of transverse sections through young ovule.

Fig. I. Just below withered apex, showing open tube.

Fig. 2. Beginning of upwardly directed flange, which is seen on right free from the tube wall, but on the left is in continuation with it. $\quad t=$ flange ; $p=$ papillate outgrowth to form flange.

Fig. 3. Shows the ingrowth of the epidermal cells of the micropylar canal and the proliferated outer epidermis of the tube.

Fig. 4. Section through the base of the widened region of the tube, just about the level of the top of the middle covering. $\mathrm{x}=$ group of cells projecting from the tip of the middle covering among the hairs of the flange.

Fig. 5. Passes through the middle and inner coverings and shows the lumen of the micropylar tube still nearly closed.

Fig. 6. A little lower; lumen widened to a triangular cavity.

Figs. 7-I 4. Series of transverse sections through large seed.

Fig. 7. Free apex of micropylar tube with cuticularized lining.

Fig. 8. Free apex of micropylar tube a little lower down, showing also top of upwardly directed flange with corky covering. $e=$ limit between flange and outermost covering.

Fig. 9. Level of origin of free flange from wall of micropylar tube; lumen nearly closed. $e=$ limit between walls of inner and outer coverings.

Fig. Io. Micropylar tube quite solid.

Fig. II. Section through region in which the wall of the tube is fewer cells thick and cavity is filled up with papillate cells.

Fig. I2. The solid mass of papillae has been torn out, leaving a cavity with a rough surface (G).

Fig. I3. Section through the base of the downwardly projecting flange; G is cavity of the tube from which the plug of cells has been torn. $g=$ gap in projecting flange, magnified half as much as Figs. 7-I3. (Between Fig. I3 and the tip of the middle covering the outer covering only is cut.)

Fig. 14. Near the tip of the middle covering, and shows the strungly lignified micropylar tube surrounded by the middle covering (o), consisting of a stony inner layer $(s t)$ and soft outer layer $(s h)$ radially expanded. Magnification as Fig. I 3 .

Fig. I5. Apex of young ovule : widely open micropylar canal with heavily cuticularized lining. $\mathrm{I}=$ wall of inner covering (micropylar tube); $\mathrm{o}=$ tip of middle covering (outer integument); $\mathrm{C}=$ outer covering.

Fig. I6. Apex of rather larger ovule, showing remains of pollen-chamber (p.c.) and some divisions in inner epidermis of micropylar tube. $\mathrm{N}=$ nucellus. 

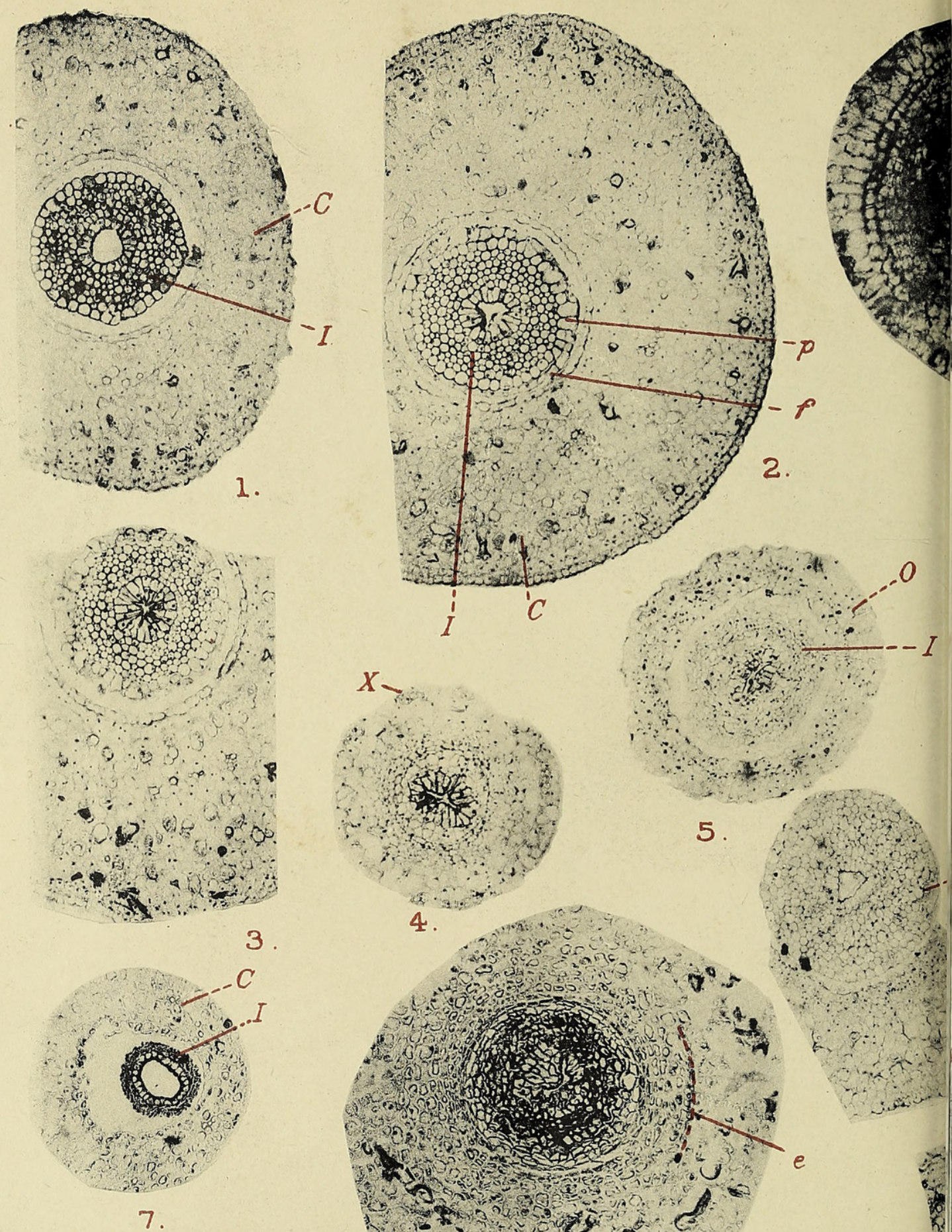

$x^{2}+2$

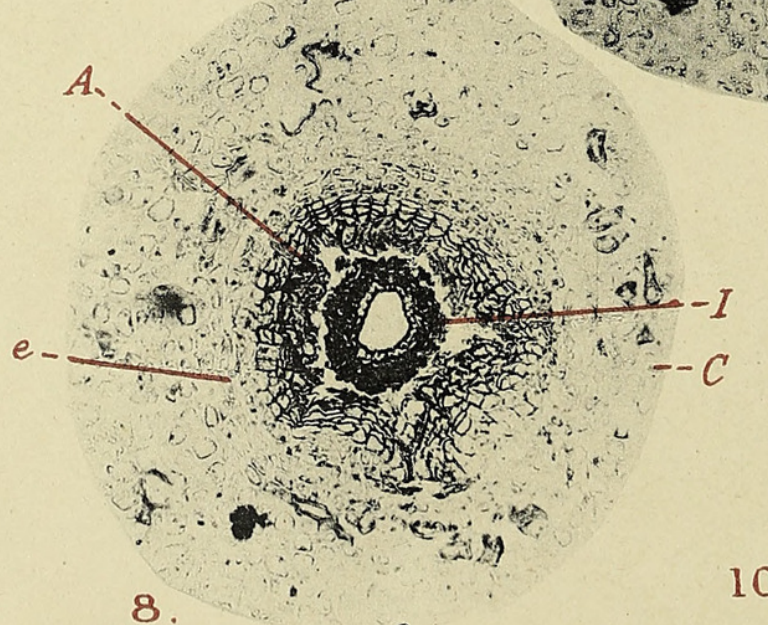

a...

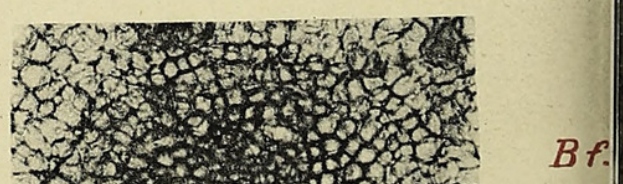

10.

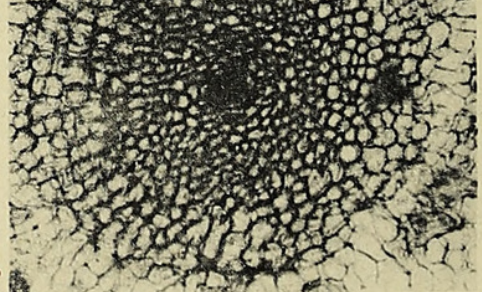



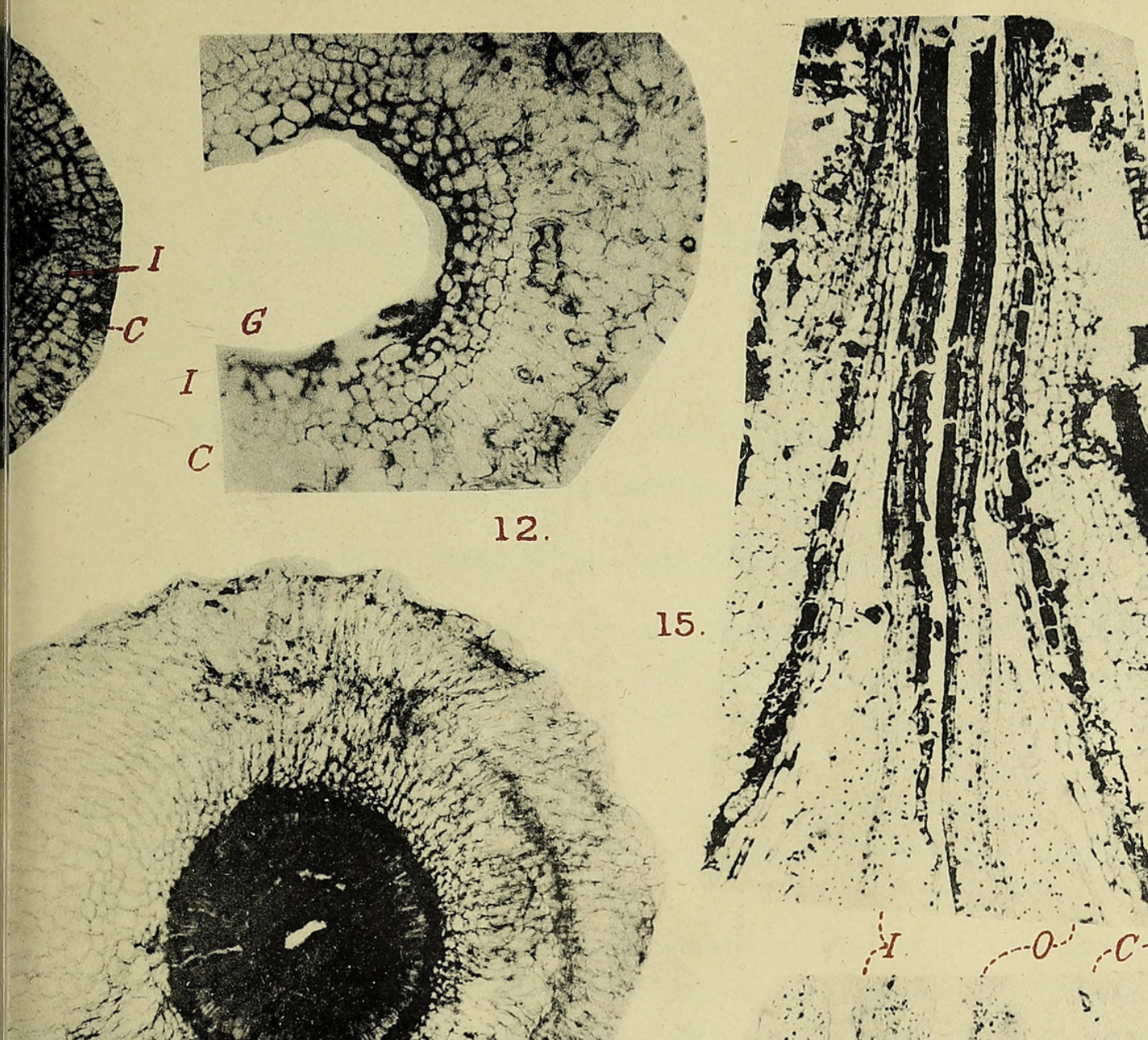

15.

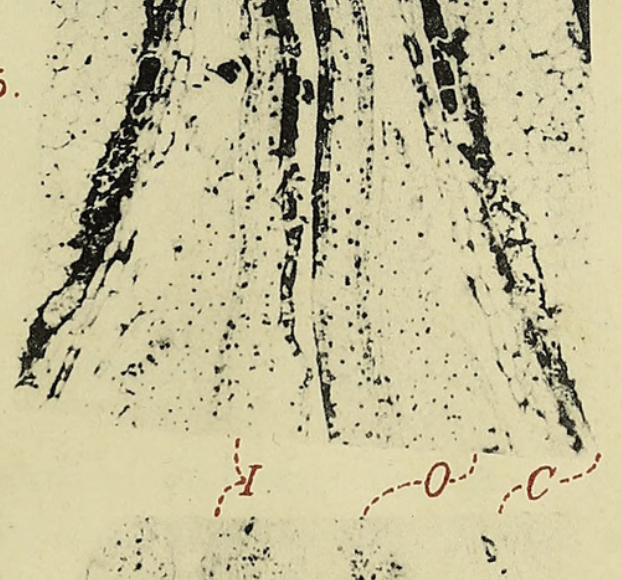

C

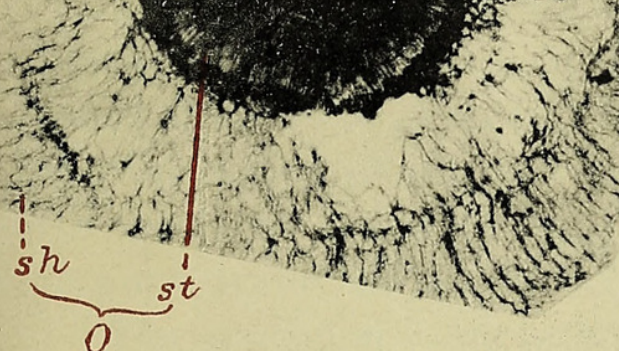

14

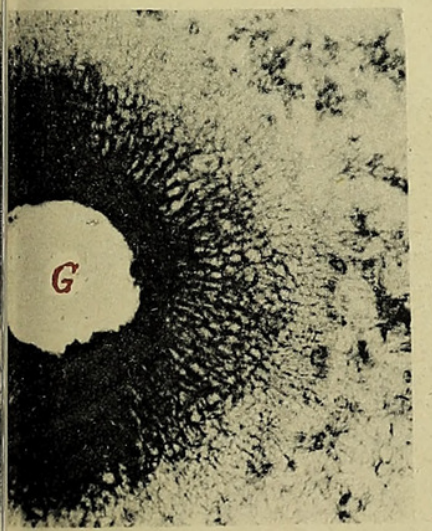

13.

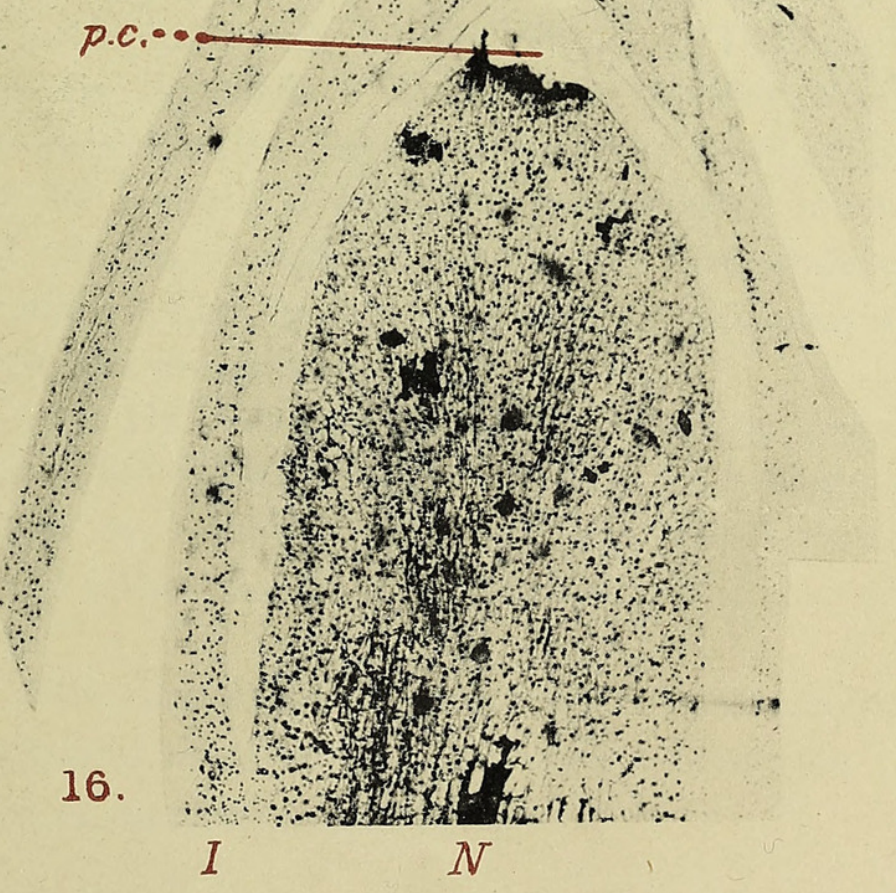


Annals of Botany,

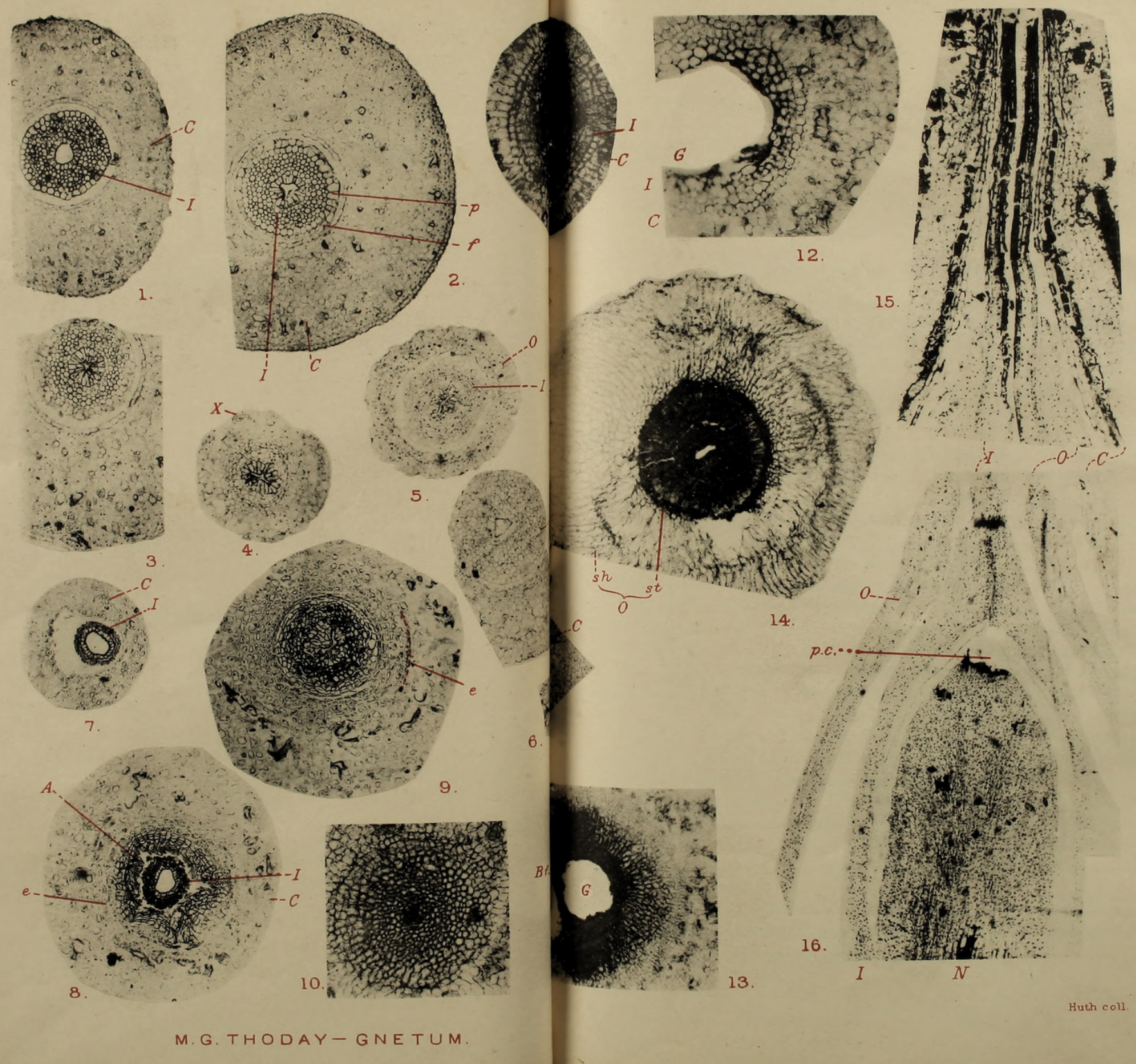




\section{$2 \mathrm{BHL}$ Biodiversity Heritage Library}

Sykes, Mary Gladys. 1921. "Anatomy of the ovule and seed in Gnetum gnemon, with notes on Gnetum funiculare." Annals of botany 35, 37-53. https://doi.org/10.1093/oxfordjournals.aob.a089746.

View This Item Online: https://www.biodiversitylibrary.org/item/235780

DOI: https://doi.org/10.1093/oxfordjournals.aob.a089746

Permalink: https://www.biodiversitylibrary.org/partpdf/318988

\section{Holding Institution}

Smithsonian Libraries

\section{Sponsored by}

Biodiversity Heritage Library

\section{Copyright \& Reuse}

Copyright Status: Not in copyright. The BHL knows of no copyright restrictions on this item.

This document was created from content at the Biodiversity Heritage Library, the world's largest open access digital library for biodiversity literature and archives. Visit BHL at https://www.biodiversitylibrary.org. 